\title{
1 Diversity and disease: evidence for the monoculture effect beyond
}

\section{2 agricultural systems}

3

\section{Authors}

5 Alice K.E. Ekroth ${ }^{1 *}$, Charlotte Rafaluk-Mohr ${ }^{1}$, Kayla C. King ${ }^{1}$

61 Department of Zoology, University of Oxford, Oxford, OX1 3PS, UK.

7 * Corresponding Author: alice.ekroth@zoo.ox.ac.uk

\section{Authorship}

A.K.E.E. and K.C.K conceived and designed the study. A.K.E.E. gathered the data and performed the statistical analysis with C.R-M. A.K.E.E. and K.C.K. wrote the paper.

Key words: Monoculture effect, genetic diversity, host-parasite interactions, specialisation, virulence, meta-analysis

\section{Acknowledgments}

We are grateful to PB Pearman, AR Wargo, P Schmid-Hempel, NK Whiteman, TD Seeley, DR

Tarpy, F Altermatt, S van Houte \& E Westra for sharing their raw data with us. We also thank

CM Lively for comments on our manuscript. A.K.E.E. acknowledges funding from Natural

Environment Research Council (NE/L002612/1). Funding was also provided by the

The authors have no competing interests. 


\section{Abstract}

27 Human activities are greatly reducing the genetic diversity of species worldwide. Given the prediction that parasites better exploit less diverse host populations, many species could be vulnerable to disease outbreaks. However, the widespread nature of the 'monoculture effect' remains unclear outside agricultural systems. We conducted a meta-analysis of 22 studies, obtaining a total of 66 effect sizes, to directly test the biological conditions under which host genetic diversity limits infectious disease in populations. Overall, we found broad support for the monoculture effect across host and parasite species. The effect was independent of host range, host reproduction, parasite diversity, and the method by which the monoculture effect was recorded. Conversely, we found that parasite functional group, virulence, and empirical environment matters. Together, these results highlight the general susceptibility of genetically homogenous populations to infection. Consequently, this phenomenon could become increasingly common and alarming for at-risk populations due to human-driven declines in genetic diversity and shifts in parasite distributions. 


\section{Introduction}

51 Most natural populations are genetically diverse (1). In host populations, genetic diversity is

52 thought to increase the chance that one or more individuals in a population is resistant to

53 infection, and thereby reduces the likelihood of a parasite encountering a susceptible host

54 (2). Genetically homogenous host populations are conversely believed to be more

55 vulnerable to infection given the uniformity of host susceptibility. This relationship between low genetic diversity and high disease incidence is referred to as the 'monoculture effect'

57 (3).

The study of the monoculture effect in agricultural settings is extensive (4-6). A recent meta-analysis showed that with increased diversity in intraspecific cultivar mixtures disease presence is reduced and crop yields increased (6). However, we know little of the extent to which the monoculture effect can occur across species and environments in natural systems and beyond agricultural contexts. Crop plants are under artificial selection for high yield, and may therefore exhibit less genetic polymorphism than those in the wild.

65

Threats to genetic diversity are on the rise. Habitat alterations, pollution, and global temperature changes, as well as the restriction of species geographical ranges may lead to higher chances of genetic drift and reduced population genetic diversity (7). Consequently, populations might suffer diminished evolutionary potential (8) and increased inbreeding depression $(9,10)$. Knowing whether there is an additional, and perhaps more immediate and intense, threat of outbreaks in these populations is crucial for disease management and species conservation approaches. 
74 Theory has illuminated the dynamics of parasite spread $(3,11-14)$ in diverse host populations as well as examined the level of diversity required to stop transmission $(15,16)$. However, the generality of the monoculture effect in nature remains unclear for several reasons. Firstly, given the infection rates of some parasites can be determined by host density (2), the relative effects of density versus host genetic diversity need to be elucidated (16). Shrinking habitats, for example, can result in higher population densities (and lower resource availability) where parasites can transmit better due to more contact between hosts $(17,18)$. Secondly, even when focusing on host genetic diversity alone, there is great variation across systems in the conditions under which infection and diversity are measured. In genetically homogenous bumble bee (Bombus terrestris L.) populations, Nosema bombi has higher success, but not Crithidia bombi, compared to diverse populations (19). In other cases, we see an increase in disease impact in homogenous host populations when infection is by multiple parasite species (19-22) but not always with specific interactions between one host-parasite species pair $(23,24)$. Thirdly, because parasite infection is measured differently across studies, and even within systems, there is the potential that the relevant measure of parasite success isn't used. For example, in honeybee (Apis mellifera) host populations, genetic diversity has a negative impact on parasite success when infection prevalence or parasite load is measured, but not always when host survival is calculated (25). Host survival might be less informative, particularly for parasites that are not obligate killers: not all hosts that are infected might die, but also host mortality can impede parasite

94 transmission if the parasite requires host-to-host contact for infection to spread. It is across the tree of life. 
98 We tested the generality of the monoculture effect with a formal meta-analysis across a range of host-parasite systems. We searched the published literature for all publicly available data sources and compared the effects of low and high host genetic diversity on parasite success using a nested random mixed effects meta-analysis model and Pearson's correlation coefficient effect size $r$ (with positive values indicating monoculture effects). We define 'parasite success' as a parasite's ability to have a high abundance in the host population whether it is measured as infection load/host, prevalence, or host mortality. We also tested whether empirical contexts or biological factors associated with the species in the interaction could explain variation in the effect of diversity on parasite success.

\section{Materials and methods}

Literature search

112 Using Web of Knowledge, Google Scholar and PubMed, we searched the literature using various combinations of the following keywords: 'host genetic diversity', 'low versus/and

114 high host genetic diversity', 'heterogeneous versus/and homogenous host populations',

115 'monoculture effect', 'disease spread', and 'parasite prevalence' to investigate the effect of

116 low versus high host population diversity on parasite disease impact (see Supp. Fig. 1 for

117 PRISMA flowchart (26) summarising study collection process). We gathered data where

118 measurements were taken of parasite success in host populations of varying genetic

119 diversity. These measurements included; parasite load, parasite virulence, parasite 

papers. Studies were also searched for and extracted from review papers.

124 Papers were included in this study if they met the following inclusion criteria:

126 i. The study was published in a peer reviewed academic journal. high diversity, inbred versus outbred, and monoculture versus polyculture.

iii. In the study, both host population groups contained the same species. community diversity or individual-level genetic heterozygosity.

137 v. The study was not conducted in an agricultural system.

139 vi. The study did not interfere with parasite or host lifecycle, as in passaging manipulations. 
143 We decided to exclude agricultural studies as a meta-analysis has already demonstrated the

144 benefits of intraspecific diversity to crop yields (and thus host fitness) in the presence of

145 infectious disease (6).

\section{Statistical analysis}

149 We calculated Pearson's correlation coefficient, $r$, from studies using the method described

150 in Field \& Gillet (2010). This measure was chosen as it allowed for a direct comparison

151 between two continuous variables, which in our case is low vs high host population

152 diversity. To calculate effect size $r$, mean parasite infection measurements and their

153 standard deviation for each treatment were extracted in the order of low host population

154 diversity and high host population diversity. We extracted data from either paper figures,

155 reported statistics in the text, or raw data received from authors. Where means and

156 standard deviations in each group were not available (2 out of 22 studies), $t$-values and

157 degrees of freedom were extracted.

159 We performed a nested random mixed effects meta-analysis model using the rma.mv

160 function in the package metafor in R version 3.6.0 (R core development team). We chose

161 this model to account for the fact that we collected several effect sizes per study, where

162 some studies shared the same host species, which has the potential for pseudo-replication and phylogenetic non-independence. We first tested for an overall relationship between

164 host population genetic diversity and parasite success using the entire dataset. Next, we tested for context dependence in the magnitude of the monoculture effects by focusing on 
reproduction, parasite functional group, host range, initial parasite diversity, and ability of between subgroups (27).

172 We tested for an effect of empirical contexts or approach on the strength of the

173 monoculture effect. In addition to dividing up studies into field or lab empirical

174 environments, we also tested an effect of the parasite success measure on the strength of

175 the monoculture effect. Thus, we separated measures into three groups; parasite

176 prevalence, parasite load, and host mortality. Studies looking at overall parasite presence in

177 a host population were placed under the category 'parasite prevalence'. Where measures of parasite propagules per host were taken, studies were placed under 'parasite load'. survival were transformed into host mortality by subtracting calculated survival data from the entire measured population.

We then focused on the impact of aspects of host and parasite biology that could explain

184 variation in the effect of host diversity on parasite success. Specifically, we tested whether

185 the strength of the monoculture effect was related to host reproductive mode, given sexual

186 and asexual strategies generate disparate levels of genetic diversity; infection by micro- or

187 macroparasites, as the former tends to be associated with higher pathogenicity (28); and

188 finally, host range (specialists or generalists), as it is assumed host resistance is genetic- 
191 to infect multiple host species. In addition, because higher levels of parasite diversity are

192 thought to increase the pool of susceptible hosts in a diverse population, we separated

193 studies into three categories - one genotype of one parasite species (1 Genotype), multiple

194 parasite genotypes of one parasite species (>1 Genotypes), and many parasite species (>1

195 Species) - to determine the importance of parasite diversity on the strength of the

196 monoculture effect. Lastly, we tested whether the parasite's ability to cause host death was

197 associated with the strength of the monoculture effect. More virulent parasites could select

198 for greater levels of resistance in the host population, whereas there may not be genetic

199 variation for resistance in diverse host populations infected by less harmful parasites.

200

201

Assessing for potential publication bias

202

Studies that report larger effects are more likely to get published in comparison to studies

204 reporting smaller effects (29). To check for publication bias, we visualised the spread of our effect sizes by creating a funnel plot (Supp. Fig. 2). We then performed a Fail-Safe $\mathrm{N}$ analysis to calculate the number of additional studies needed to reduce the significance level of the weighted average effect size (30).

\section{Results}

211 We found 22 papers containing data to answer the research question and followed the

212 inclusion criteria. Papers often included results from multiple experiments or exposures to

213 multiple parasite species. A total of 66 effect sizes were retrieved from this data set,

214 covering a diverse range of host and parasite species (Table 1). 
216 After the construction of a funnel plot, we find no indication of a publication bias in this

217 meta-analysis data set, with the majority of points falling within the plot (Supp. Fig. 1).

218 Rosenberg's Fail-safe $\mathrm{N}$ analysis showed that an additional 644 studies would need to be

219 added to reduce the significance level of this meta-analysis.

220

221 Our results are consistent with the monoculture effect hypothesis, showing that low host genetic diversity increases parasite success $(r=0.3950, z=3.1349, p<0.0001$, Fig. 1A). We

223 found that the strength of the direction of the effect size is influenced by empirical significantly differ from lab studies $(r=0.1077)$. However, parasite infection measures (i.e. parasite load, parasite prevalence, or host mortality) do not significantly influence the effect size $(Q=3.5302$, d.f. $=2, p=0.1712$, Fig. $1 C)$.

We examined the impact of a suite of host and parasite characteristics on the strength of the monoculture effect. We found that host reproduction was not a factor that significantly

231 influenced the strength of the effect size $(Q=3.7744$, d.f. $=2, p=0.1515$, Fig. $2 A)$. A study by Altermatt \& Ebert (2008) followed parasite infection of Daphnia during both sexual and asexual reproduction, and was thus placed as a separate variable. We then focused on parasite characteristics, we found that parasite functional group significantly influenced the strength of the direction of the effect size $(Q=8.7057$, d.f. $=1, p=0.0032$, Fig. 2B). Where macroparasites ( $r=-0.0091)$ had mostly no or a slightly negative impact, but microparasites $(r=0.2298)$ showed a strong, positive impact. The direction of the effect size was found not to be influenced by host range $(Q=0.2771$, d.f. $=1, p=0.5986$, Fig. $2 C)$. We also found that 
parasite diversity was not a significant factor on the strength of the monoculture effect $(Q=$ studies using parasites that could kill hosts showed a stronger monoculture effect $(r=$

\section{Discussion}

249 Our meta-analysis shows that host population genetic diversity reduces parasite success

250 across multiple systems, approaches, and environments. Indeed, the monoculture effect is revealed under the majority of the biological variables we tested in the host-parasite relationship, but that microparasites and parasites that kill are more likely to encounter differences in resistance in host populations varying in diversity. Our findings additionally highlight the potential damage that emerging infectious diseases may have on genetically homogenous host populations, given that the monoculture effect is not dependent on a parasite's host range.

The parasites included in our meta-analysis were highly variable in terms of their host range. However, we show that the monoculture effect is independent of a parasite's host range. Indeed, the monoculture effect is equally as prevalent in highly specialised interactions (31-

261 33), in broad spectrum interactions at the genotypic level (34), and in those that cross host- 
results found in crop studies. For example, in rusts and powdery mildews, disease severity is resistance genes means that crop mixtures need to contain both susceptible and resistant cultivars to avoid a monoculture effect. When there is a lack of host specificity, mixed cultivar populations are just as susceptible as monocultures. For example, mixed cultivar populations have been observed to be slightly more susceptible to infection (36) or completely susceptible (37) in comparison to monocultures to the fungal pathogen Mycosphaerella graminicola. These findings suggest that the threat to crops from generalist parasites is greater than specialist parasites.

272

273 Given that host range did not influence the strength of the monoculture effect, it is possible that novel parasites, just as adapted parasites, could have high success in host monocultures. Essentially, homogenous populations could be vulnerable to outbreaks with spill-over or emerging infectious diseases which are less likely to be host specific (38), but

277 for which there is clearly genetic variation for resistance. The resistance to emerging parasites in these cases could be due to historical contact or similar mechanisms of infection to parasites with an evolutionary history with the host (39). Nevertheless, this result is concerning from a conservation perspective as global climate change has the potential to reduce within-species genetic diversity $(40)$ and alter host population ranges $(41,42)$.

282 Natural movement of individuals between populations has always served to bolster host diversity (42), and introducing new genotypes is an approach applied by conservation biologists to improve population viability (10). Whilst adding individuals to a population could increase diversity and reduce inbreeding (43), a risk may be that new individuals bring 
studies, these consequences are of real concern. The potential being an increased overlap between host populations with low genetic diversity and novel infections.

The fact that we found a stronger monoculture effect in field studies highlights the importance of the maintenance of diversity in natural populations. As hosts are exposed to a greater variety of parasites in the field, there could be higher levels of resistance already present in diverse populations (39). Thus, when host diversity is artificially reduced (21), parasites normally unable to rapidly spread through a host population can now infect with minimal selection on virulence evolution. In addition, secluded host populations, such as island populations of Galapagos hawks (22), are naturally considered inbred compared to their main land or larger island counter parts and are therefore more vulnerable to infection. Also, island populations as well as social insects, such as bees (45), ants (46), and termites (47), live in tight proximities to each other making parasite transmission easier in homogenous populations. Indeed, despite being subjected to environmental noises, the monoculture effect is strong in the natural environment.

In our meta-analysis, macroparasites were not impeded by genetic heterogeneity in host populations. The macroparasites in the studies included herein are all ectoparasites, and their biology may explain why. Their transmission is often dependent on host-to-host contact $(48,49)$ and thus host density is a critical factor in parasite success $(48)$. Host density may play a more important role than host genetic diversity such that similarly aggregated populations of either genetically high or low host populations might be equally susceptible to infection. It has been shown that clustering of captive animal populations restricted by 
ectoparasites $(44,50)$. Moreover, host social behaviours, such as grooming $(25)$ or preening

312 (22) can reduce ectoparasite success. In fact, in populations where social grooming is correlated with relatedness, ectoparasite load is dramatically reduced in highly related

314 individuals (51). Taken together, host diversity on its own does not always explain a

315 reduction in parasite success, particularly in the case of ectoparasites.

317 We reveal that the monoculture effect is more likely to be observed in systems with a

318 parasite that can cause host mortality. This outcome may stem from greater selection for

319 resistance in diverse host populations at risk of infection and death from parasites (52). Whilst some parasites in the relevant studies are obligate killers, such as bacteriophages

321 (33), some merely have the potential to cause host mortality. For example, Crithidia bombi can cause in mortality in bumble bees (Bombus spp) when the colony is stressed by lack of access to food sources (53). It is nevertheless possible that host population genetic diversity, as measured in the studies with less virulent parasites, may not be correlated with diversity in resistance per se.

327 Understanding the impact of reduced genetic diversity on parasite infection outside of agricultural systems is crucial because of anthropogenic threats to the diversity of wild populations. This meta-analysis reveals that the monoculture effect is a widespread phenomenon across host and parasite species in nature, with microparasites and host-killing parasites being the most likely to encounter resistance in diverse host populations. Indeed,

332 these broad patterns show that genetic diversity is a robust weapon against infection, but that further attacks on diversity could drive outbreaks of both coevolving and emerging

334 infectious diseases. However, these results suggest that conservation efforts should focus 


\section{References}

1. Haldane JBS. Suggestions as to Quantitative Measurement of Rates of Evolution. Evolution. 1949;3(1):51-6.

2. Anderson RM, May RM. Coevolution of hosts and parasites. Parasitology. 1982;85(02):411.

3. Elton CS. The Ecology of Invasions by Animals and Plants. University of Chicago Press; 1958. $226 \mathrm{p}$.

4. Smithson JB, Lenné JM. Varietal mixtures: a viable strategy for sustainable productivity in subsistence agriculture. Annals of Applied Biology. 1996;128(1):127-58.

5. Mundt CC. Use of Multiline Cultivars and Cultivar Mixtures for Disease Management. Annual Review of Phytopathology. 2002;40(1):381-410.

6. Reiss ER, Drinkwater LE. Cultivar mixtures: a meta-analysis of the effect of intraspecific diversity on crop yield. Ecological Applications. 2018;28(1):62-77.

7. Swaegers J, Mergeay J, Therry L, Larmuseau MHD, Bonte D, Stoks R. Rapid range expansion increases genetic differentiation while causing limited reduction in genetic diversity in a damselfly. Heredity. 2013;111(5):422-9.

8. Frankham R, Ballou JD, Ralls K, Eldridge M, Dudash MR, Fenster CB, et al. Genetic Management of Fragmented Animal and Plant Populations. Oxford University Press; 2017. 426 p.

9. Spielman D, Brook BW, Briscoe DA, Frankham R. Does Inbreeding and Loss of Genetic Diversity Decrease Disease Resistance? Conservation Genetics. 2004;5(4):439-48.

10. Charlesworth $\mathrm{D}$, Willis $\mathrm{JH}$. The genetics of inbreeding depression. Nature Reviews Genetics. 2009;10(11):783-96.

11. Schmid-Hempel P. Parasites in Social Insects. Princeton University Press; 1998. 428 p. 
13. Keesing F, Holt RD, Ostfeld RS. Effects of species diversity on disease risk. Ecology Letters. 2006;9(4):485-98.

14. Nath M, Woolliams JA, Bishop SC. Assessment of the dynamics of microparasite infections in genetically homogeneous and heterogeneous populations using a stochastic epidemic model1. Journal of Animal Science. 2008;86(8):1747-57.

15. Lively CM. The Effect of Host Genetic Diversity on Disease Spread. The American Naturalist. 2010;175(6):149-52.

16. King KC, Lively CM. Does genetic diversity limit disease spread in natural host populations? Heredity. 2012;109(4):199-203.

17. May RM. Conservation and Disease. Conservation Biology. 1988;2(1):28-30.

18. Loehle C. Social Barriers to Pathogen Transmission in Wild Animal Populations. Ecology. 1995;76(2):326-35.

19. Baer B, Schmid-Hempel P. Experimental variation in polyandry affects parasite loads and fitness in a bumble-bee. Nature. 1999;397(6715):151-4.

20. Baer B, Schmid-Hempel P. Unexpected Consequences of Polyandry for Parasitism and Fitness in the Bumblebee, Bombus terrestris. Evolution. 2001;55(8):1639-43.

21. Baer B, Schmid-Hempel P. Bumblebee workers from different sire groups vary in susceptibility to parasite infection. Ecology Letters. 2003;6(2):106-10.

22. Whiteman NK, Matson KD, Bollmer JL, Parker PG. Disease ecology in the Galápagos Hawk (Buteo galapagoensis): host genetic diversity, parasite load and natural antibodies. Proceedings of the Royal Society of London B: Biological Sciences. 2006;273(1588):797-804.

23. Reber A, Castella G, Christe $P$, Chapuisat $M$. Experimentally increased group diversity improves disease resistance in an ant species. Ecology Letters. 2008;11(7):682-9.

24. Schmidt AM, Linksvayer TA, Boomsma JJ, Pedersen JS. No benefit in diversity? The effect of genetic variation on survival and disease resistance in a polygynous social insect. Ecological Entomology. 2011;36(6):751-9.

25. Desai SD, Currie RW. Genetic diversity within honey bee colonies affects pathogen load and relative virus levels in honey bees, Apis mellifera L. Behav Ecol Sociobiol. 2015;69(9):1527-41.

26. Moher D, Liberati A, Tetzlaff J, Altman DG. Preferred Reporting Items for Systematic Reviews and Meta-Analyses: The PRISMA Statement. Annals of Internal Medicine. 2009;151(4):264.

27. Schwarzer G, Carpenter JR, Rücker G. Fixed Effect and Random Effects Meta-Analysis. In: Schwarzer G, Carpenter JR, Rücker G, editors. Meta-Analysis with R. Cham: Springer 
International Publishing; 2015. p. 21-53. Available from: https://doi.org/10.1007/9783-319-21416-0_2

28. Anderson RM, May RM. The invasion, persistence and spread of infectious diseases within animal and plant communities. 1986;38.

29. Borenstein M, Hedges LV, Higgins JPT, Rothstein HR. Introduction to Meta-Analysis. John Wiley \& Sons; 2009. 434 p.

30. Rosenberg MS. The file-drawer problem revisited: A general weighted method for calculating fail-safe numbers in meta-analysis. Evolution. 2005;59(2):464.

31. Altermatt F, Ebert D. Genetic diversity of Daphnia magna populations enhances resistance to parasites. Ecology Letters. 2008;11(9):918-28.

32. Wargo AR, Kell AM, Scott RJ, Thorgaard GH, Kurath G. Analysis of host genetic diversity and viral entry as sources of between-host variation in viral load. Virus Research. 2012;165(1):71-80.

33. van Houte $\mathrm{S}$ van, Ekroth AKE, Broniewski JM, Chabas H, Ashby B, Bondy-Denomy J, et al. The diversity-generating benefits of a prokaryotic adaptive immune system. Nature. 2016;532(7599):385-8.

34. Pearman PB, Garner TWJ. Susceptibility of Italian agile frog populations to an emerging strain of Ranavirus parallels population genetic diversity. Ecology Letters. 2005;8(4):401-8.

35. Hale KA, Briskie JV. Decreased immunocompetence in a severely bottlenecked population of an endemic New Zealand bird. Animal Conservation. 2006;10(1):2-10.

36. Gigot C, Saint-Jean S, Huber L, Maumené C, Leconte M, Kerhornou B, et al. Protective effects of a wheat cultivar mixture against splash-dispersed septoria tritici blotch epidemics. Plant Pathology. 2013;62(5):1011-9.

37. Cowger C, Mundt CC. Effects of Wheat Cultivar Mixtures on Epidemic Progression of Septoria Tritici Blotch and Pathogenicity of Mycosphaerella graminicola. Phytopathology. 2002;92(6):617-23.

38. Brooks DR, Hoberg EP. How will global climate change affect parasite-host assemblages? Trends in Parasitology. 2007;23(12):571-4.

39. Altizer S, Harvell D, Friedle E. Rapid evolutionary dynamics and disease threats to biodiversity. Trends in Ecology \& Evolution. 2003;18(11):589-96.

40. Hoffmann AA, Sgrò CM. Climate change and evolutionary adaptation. Nature. 2011;470(7335):479-85.

41. Bálint M, Domisch S, Engelhardt CHM, Haase P, Lehrian S, Sauer J, et al. Cryptic biodiversity loss linked to global climate change. Nature Climate Change. 2011;1(6):313-8. 
42. Pauls SU, Nowak C, Bálint M, Pfenninger M. The impact of global climate change on genetic diversity within populations and species. Molecular Ecology. 2013;22(4):92546.

43. Frankham R. Conservation Genetics. Annual Review of Genetics. 1995;29(1):305-27.

44. Altizer S, Bartel R, Han BA. Animal Migration and Infectious Disease Risk. Science. 2011;331(6015):296-302.

45. Tarpy DR, Seeley TD. Lower disease infections in honeybee Apis mellifera colonies headed by polyandrous vs monandrous queens. Naturwissenschaften. 2006;93(4):1959 .

46. Hughes $\mathrm{WOH}$, Boomsma JJ. Genetic diversity and disease resistance in leaf-cutting ant societies. Evolution. 2004;58(6):1251-60.

47. Calleri DV, Reid EM, Rosengaus RB, Vargo EL, Traniello JFA. Inbreeding and disease resistance in a social insect: effects of heterozygosity on immunocompetence in the termite Zootermopsis angusticollis. Proceedings of the Royal Society of London B: Biological Sciences. 2006;273(1601):2633-40.

48. Viney M, Cable J. Macroparasite Life Histories. Current Biology. 2011;21(18):767-74.

49. Whiteman NK, Parker PG. Effects of Host Sociality on Ectoparasite Population Biology. The Journal of Parasitology. 2004;90(5):939-47.

50. Scott ME. The Impact of Infection and Disease on Animal Populations: Implications for Conservation Biology. Conservation Biology. 1988;2(1):40-56.

51. Frumhoff PC, Schneider S. The social consequences of honey bee polyandry: the effects of kinship on worker interactions within colonies. Animal Behaviour. 1987;35(1):25562.

52. Gómez P, Buckling A. Bacteria-Phage Antagonistic Coevolution in Soil. Science. 2011;332(6025):106-9.

53. Schmid-Hempel P. On the evolutionary ecology of host-parasite interactions: addressing the question with regard to bumblebees and their parasites. Naturwissenschaften. 2001;88(4):147-58. 
470 Table 1: Summary of literature on the effect of host population genetic diversity on

471 measures of parasite success across host-parasite systems.

472

473 Figure 1: Impact of study approach on the effect of host genetic diversity on parasite

474 success. Positive values indicate a monoculture effect is present (i.e., a negative association

475 between genetic diversity and parasite success). Negative values represent the opposite

476 relationship. At an effect size of zero (dashed line), there is no relationship between host

477 genetic diversity and parasite success. (A) Overall effect size $(n=66)$. (B) Moderator analysis

478 of study type between field $(n=36)$ and lab $(n=30)$ studies. (C) Moderator analysis of

479 parasite infection measures between parasite load $(n=19)$, parasite prevalence $(n=34)$,

480 and host mortality $(n=13)$. The size of the dot corresponds to the sample size. Effect sizes

481 are shown with $95 \%$ confidence intervals.

482

483 Figure 2: Impact of host and parasite characteristics on the effect of host genetic diversity

484 on parasite success. Positive values indicate a monoculture effect (i.e., a negative

485 association between genetic diversity and parasite success). Negative values represent the

486 opposite relationship. The dashed line (effect size of zero) represents no relationship

487 between host genetic diversity and disease spread. Moderator analysis of $(A)$ host

488 reproduction mode: asexual $(n=5)$, both $(n=2)$, and sexual $(n=59)$ effect sizes, (B) of

489 parasite functional group between microparasite $(n=56)$ and macroparasite $(n=10)$ effect

490 sizes, (C) host range between specific $(n=15)$ and general $(n=51)$ parasite effect sizes, (D)

491 initial parasite diversity between $>1$ genotype $(n=14), 1$ genotype $(n=15)$, and $>1$ species $(n$

$492=37$ ) effect sizes, and (E) of the ability of a parasite to cause host death, displayed as yes ( $\mathrm{n}$ 
bioRxiv preprint doi: https://doi.org/10.1101/668228; this version posted June 12, 2019. The copyright holder for this preprint (which was

not certified by peer review) is the author/funder, who has granted bioRxiv a license to display the preprint in perpetuity. It is made available under aCC-BY-NC-ND 4.0 International license.

$493=56)$ and no $(n=10)$ effect sizes. The size of the dot corresponds to the sample size. Effect

494 sizes are shown with 95\% confidence intervals.

495 
这

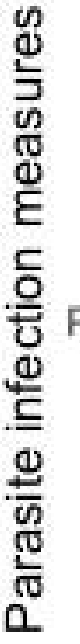

Parasite load -

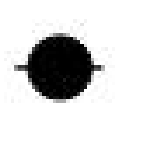

Mortality 


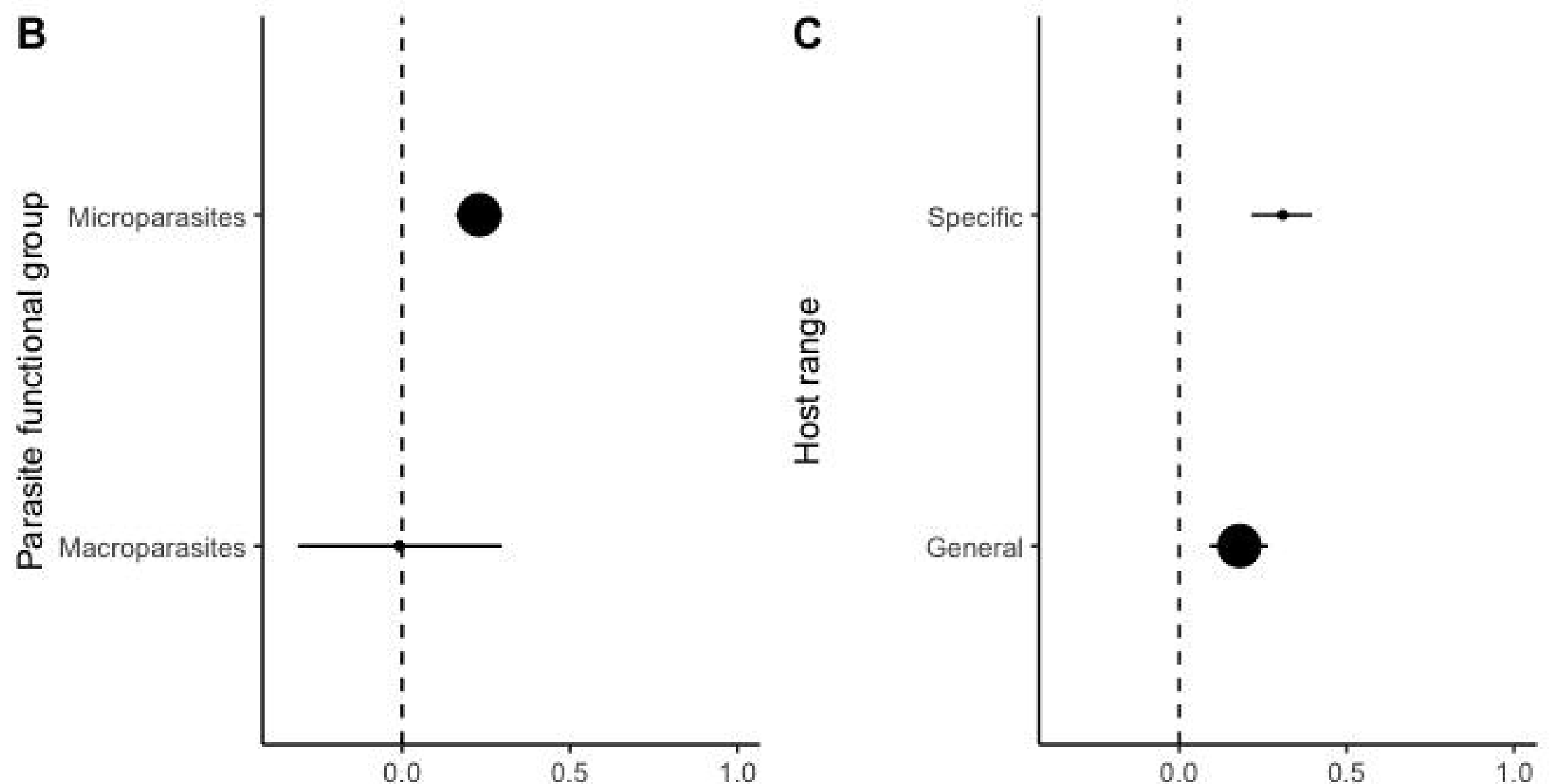

Parasite success effect size

Parasite success effect size

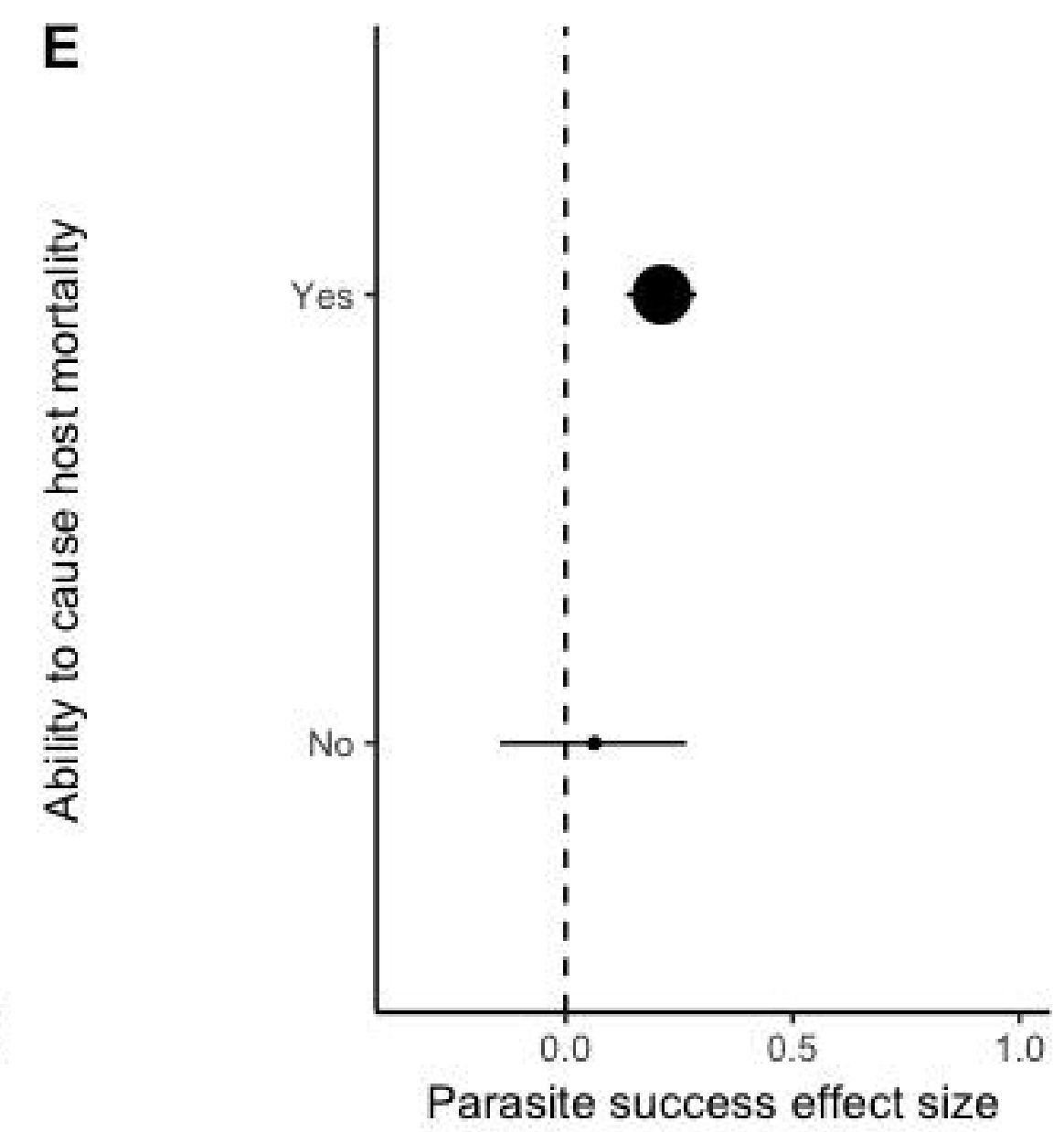

Parasite success effect size

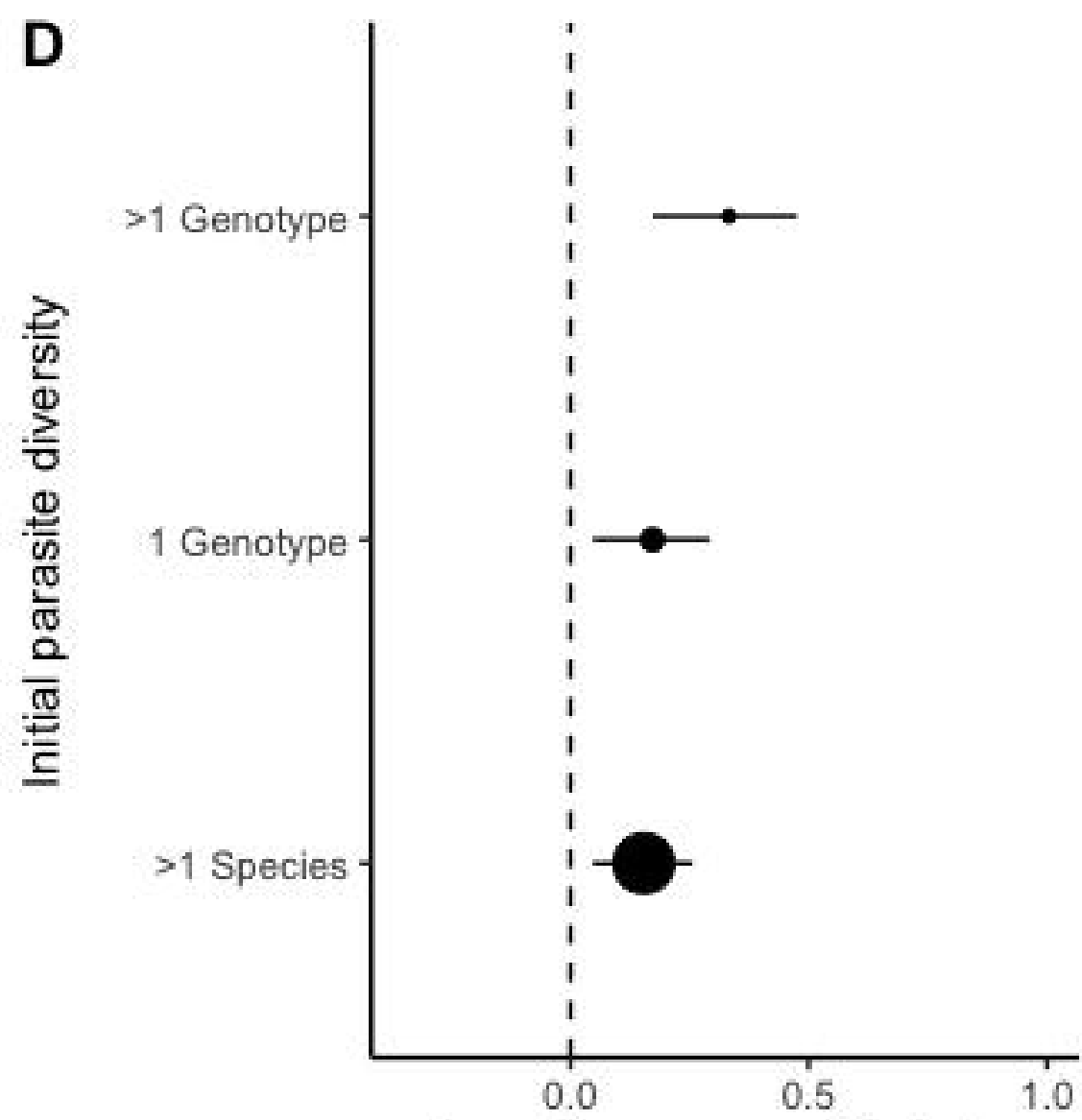

Parasite success effect size 
Table 1: Summary of literature on the effect of host population genetic diversity on measures of parasite success across host-parasite systems.

\begin{tabular}{|c|c|c|c|c|c|c|c|c|}
\hline Source & Paper & Host & Parasite & Parasite & Infection & Data & Data & n Effect \\
\hline paper & numbe & & & type & measure & source & extracted & sizes \\
\hline
\end{tabular}

\begin{tabular}{|c|c|c|c|c|c|c|c|c|}
\hline Altermatt & 1 & Daphnia magna & Octosporea bayeri & Fungus & Parasite load & Figure 2, & Mean \pm SD & 2 \\
\hline and Ebert & & & & & & Raw data & & \\
\hline
\end{tabular}

(2008)

\begin{tabular}{|c|c|c|c|c|c|c|c|c|}
\hline Baer and & 2 & Bumblebee (Bombus & Crithidia bombi, & Protozoa, & Parasite load & Figure 1, & Mean \pm SE & 4 \\
\hline Schmid- & & terrestris) & Nosema bombi & Fungus & & Raw data & & \\
\hline \multicolumn{9}{|l|}{ Hempel } \\
\hline \multicolumn{9}{|l|}{ (1999) } \\
\hline Baer and & 3 & Bumblebee (Bombus & Crithidia bombi & Protozoa & Parasite load, & Figure 1, & Mean \pm SD & 4 \\
\hline Schmid- & & terrestris) & & & & Raw data & & \\
\hline
\end{tabular}


Hempel

(2001)

Baer and

Schmid-

Hempel
Parasite

prevalence

(2003)

\begin{tabular}{|c|c|c|c|c|c|c|c|c|}
\hline $\begin{array}{l}\text { Calleri et al. } \\
\text { (2006) }\end{array}$ & 5 & $\begin{array}{l}\text { Termite } \\
\text { (Zootermopsis } \\
\text { angusticollis) }\end{array}$ & $\begin{array}{l}\text { Metarhizium } \\
\text { anisopliae }\end{array}$ & Fungus & Parasite load & In text & Mean \pm SD & 1 \\
\hline Desai and & 6 & Honeybee (Apis & Varroa destructor, & Mite, & Parasite load, & Figure 1, & Mean \pm SE & 11 \\
\hline \multirow[t]{3}{*}{ Currie (2015) } & & mellifera L.) & Deformed Wing & Virus, & Host mortality, & $2,4,5,7$ & & \\
\hline & & & Virus, & Virus, & Parasite & 8 & & \\
\hline & & & & Virus & prevalence & & & \\
\hline
\end{tabular}


Black Queen Cell

Virus,

Israeli Acute

Paralysis Virus

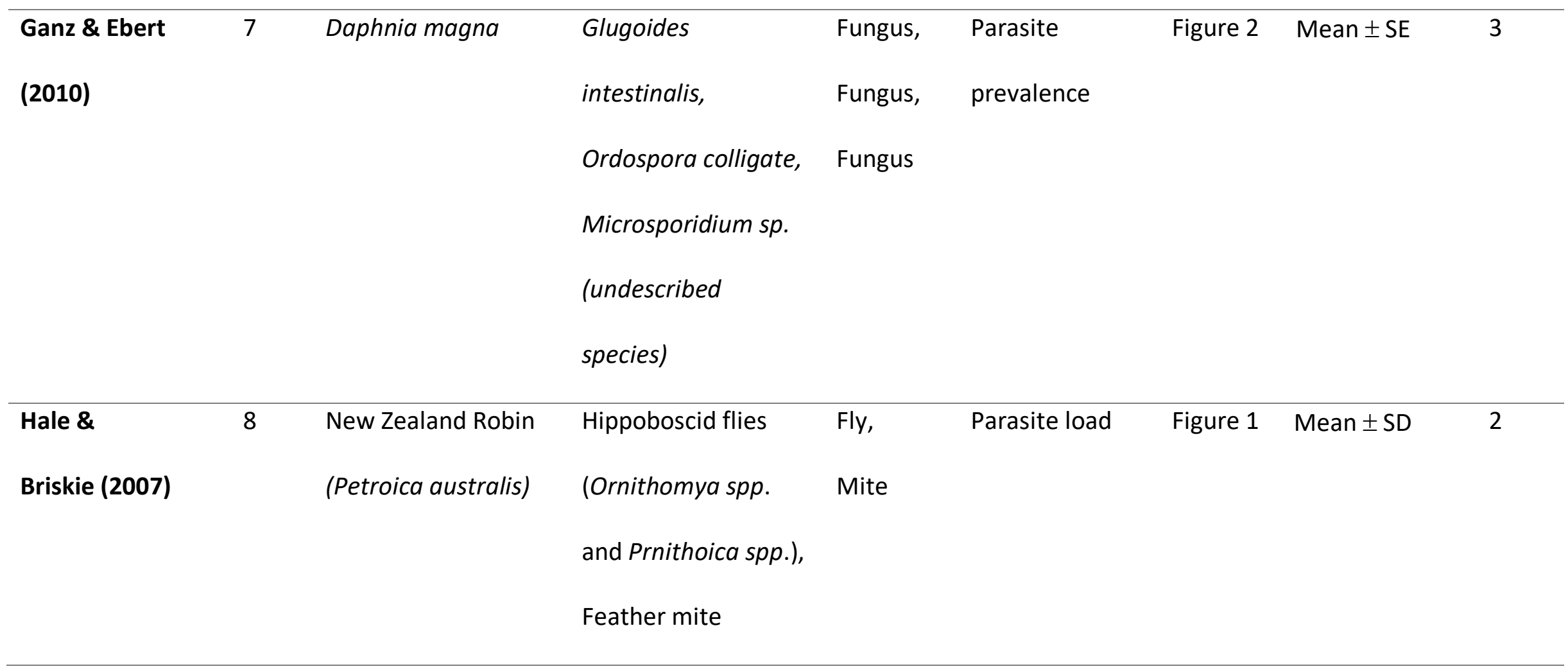




\begin{tabular}{|c|c|c|c|c|c|c|c|c|}
\hline Hughes \& & 9 & Ant (Acromyrmex & Metarhizium & Fungus & Host mortality & Figure 4 & Mean \pm SE & 2 \\
\hline Boomsma & & echinatior) & anisopliae (strain & & & & & \\
\hline (2004) & & & KVL 02-73) & & & & & \\
\hline Liersch and & 10 & Bumblebee (Bombus & Crithidia bombi, & Protozoa, & Parasite & Figure 1 & Mean $+\mathrm{Cl}$ & 2 \\
\hline Schmid- & & terrestris) & Nosema bombi, & Fungus, & prevalence, & & & \\
\hline Hempel & & & Apicystis (Mattesia) & Protozoa & Parasite load & & & \\
\hline (1998) & & & bombi & & & & & \\
\hline
\end{tabular}

\begin{tabular}{|c|c|c|c|c|c|c|c|c|}
\hline $\begin{array}{l}\text { Manlik et al. } \\
\text { (2017) }\end{array}$ & 11 & $\begin{array}{l}\text { Bumblebee (Bombus } \\
\text { terrestris) }\end{array}$ & Nosema bombi & Fungus & $\begin{array}{l}\text { Parasite } \\
\text { prevalence }\end{array}$ & In text & Mean \pm SE & 1 \\
\hline $\begin{array}{l}\text { Pearman \& } \\
\text { Garner (2005) }\end{array}$ & 12 & $\begin{array}{l}\text { Italian agile frog } \\
\text { (Rana latastei) }\end{array}$ & $\begin{array}{l}\text { Ranavirus (frog virus } \\
\text { 3) }\end{array}$ & Virus & Host mortality & $\begin{array}{l}\text { Figure 2, } \\
\text { Raw data }\end{array}$ & Mean \pm SD & 3 \\
\hline $\begin{array}{l}\text { Reber et al. } \\
\text { (2008) }\end{array}$ & 13 & Ant (Formica selysi) & $\begin{array}{l}\text { Metarhizium } \\
\text { anisopliae }\end{array}$ & Fungus & Host mortality & $\begin{array}{c}\text { Figure 1, } \\
2\end{array}$ & Mean \pm SE & 3 \\
\hline
\end{tabular}




\begin{tabular}{|c|c|c|c|c|c|c|c|c|}
\hline $\begin{array}{l}\text { Schmidt et al. } \\
\text { (2011) }\end{array}$ & 14 & $\begin{array}{l}\text { Ant (Monomorium } \\
\text { pharaonis) }\end{array}$ & Beauveria bassiana & Fungus & Host mortality & Figure 3 & Mean $+\mathrm{Cl}$ & 3 \\
\hline Seeley and & 15 & Honeybee (Apis & American foulbrood & Bacteria & Parasite & Figure 2, & Mean \pm SD & 2 \\
\hline Tarpy (2007) & & mellifera L.) & (Paenibacillus & & prevalence & Raw data & & \\
\hline
\end{tabular}

\begin{tabular}{|c|c|c|c|c|c|c|c|c|}
\hline Shykoff and & 16 & Bumblebee (Bombus & Crithidia bombi & Protozoa & Parasite & Figure 2 & $\mathrm{t}$-value & 2 \\
\hline Schmid- & & terrestris) & & & prevalenc & & & \\
\hline
\end{tabular}

Hempel

(1991)

\begin{tabular}{|c|c|c|c|c|c|c|c|c|}
\hline Smallbone et & 17 & Guppy (Poecilia & Gyrodactylus & Worm & Parasite load & Figure 2 & Mean \pm SE & 1 \\
\hline al. (2016) & & reticulata) & turnbulii (strai & & & & & \\
\hline
\end{tabular}




\begin{tabular}{|c|c|c|c|c|c|c|c|c|}
\hline Tarpy (2003) & 18 & $\begin{array}{l}\text { Honeybee (Apis } \\
\text { mellifera L.) }\end{array}$ & $\begin{array}{l}\text { Chalkbrood disease } \\
\text { (Acosphaera apis) }\end{array}$ & Fungus & $\begin{array}{l}\text { Parasite } \\
\text { prevalence }\end{array}$ & Figure 2 & Mean \pm SD & 1 \\
\hline $\begin{array}{l}\text { Tarpy and } \\
\text { Seeley (2006) }\end{array}$ & 19 & $\begin{array}{l}\text { Honeybee (Apis } \\
\text { mellifera L.) }\end{array}$ & $\begin{array}{l}\text { Sacbrood (Iflavirus } \\
\text { genus), } \\
\text { Chalkbrood disease } \\
\text { (Acosphaera apis), } \\
\text { European foulbrood } \\
\text { (Melissococcus } \\
\text { plutonius), } \\
\text { American foulbrood } \\
\text { (Paenibacillus } \\
\text { larvae) }\end{array}$ & $\begin{array}{l}\text { Virus, } \\
\text { Fungus, } \\
\text { Bacteria, } \\
\text { Bacteria }\end{array}$ & $\begin{array}{l}\text { Parasite } \\
\text { prevalence }\end{array}$ & In text & $\mathrm{t}$ - value & 4 \\
\hline $\begin{array}{l}\text { van Houte et } \\
\text { al. (2016) }\end{array}$ & 20 & $\begin{array}{l}\text { Pseudomonas } \\
\text { aeruginosa, }\end{array}$ & $\begin{array}{l}\text { Bacteriophage } \\
\text { (DMS3), }\end{array}$ & $\begin{array}{l}\text { Virus, } \\
\text { Virus }\end{array}$ & $\begin{array}{l}\text { Parasite } \\
\text { prevalence }\end{array}$ & $\begin{array}{l}\text { Figure 2, } \\
\text { Raw data }\end{array}$ & Mean \pm SD & 5 \\
\hline
\end{tabular}




\begin{tabular}{|c|c|c|c|c|c|c|c|c|}
\hline & & $\begin{array}{l}\text { Streptococcus } \\
\text { thermophilus }\end{array}$ & $\begin{array}{l}\text { Bacteriophage } \\
(2972)\end{array}$ & & & & & \\
\hline $\begin{array}{l}\text { Wargo et al. } \\
\text { (2012) }\end{array}$ & 21 & $\begin{array}{l}\text { Rainbow trout } \\
\text { (Oncorhynchus } \\
\text { mykiss) }\end{array}$ & $\begin{array}{l}\text { Infectious } \\
\text { hematopoietic } \\
\text { necrosis virus (IHNV) } \\
\text { isolates: } \\
\text { 220:90 (HV), } \\
\text { WRAC 039-82 (LV), } \\
\text { FF020-91 (B), } \\
\text { FF030-91(C) }\end{array}$ & Virus & $\begin{array}{l}\text { Parasite } \\
\text { prevalence }\end{array}$ & $\begin{array}{l}\text { Figure 2, } \\
\text { Raw data }\end{array}$ & Mean \pm SE & 4 \\
\hline $\begin{array}{l}\text { Whiteman et } \\
\text { al. (2006) }\end{array}$ & 22 & $\begin{array}{l}\text { Galapagos Hawk } \\
\text { (Buteo } \\
\text { galapagoensis) }\end{array}$ & $\begin{array}{l}\text { Colpocephalum } \\
\text { turbinatum, } \\
\text { Degeerialla regalis }\end{array}$ & $\begin{array}{l}\text { Louse, } \\
\text { Louse }\end{array}$ & Parasite load & $\begin{array}{l}\text { Figure 2, } \\
\text { Raw data }\end{array}$ & Mean \pm SD & 2 \\
\hline
\end{tabular}


